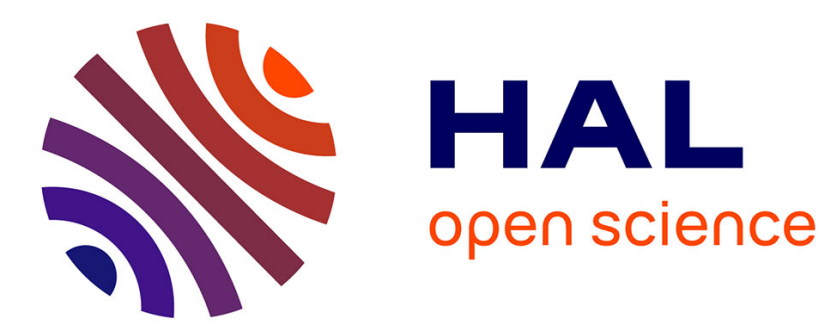

\title{
Land evaluation methodology and GIS for soil resource management. Example with cotton crop in Greece
}

\author{
Vassiliki J. Kollias, Dionissios P. Kalivas
}

\section{To cite this version:}

Vassiliki J. Kollias, Dionissios P. Kalivas. Land evaluation methodology and GIS for soil resource management. Example with cotton crop in Greece. Agronomie, 1999, 19 (2), pp.107-118. hal00885918

\section{HAL Id: hal-00885918 https://hal.science/hal-00885918}

Submitted on 1 Jan 1999

HAL is a multi-disciplinary open access archive for the deposit and dissemination of scientific research documents, whether they are published or not. The documents may come from teaching and research institutions in France or abroad, or from public or private research centers.
L'archive ouverte pluridisciplinaire HAL, est destinée au dépôt et à la diffusion de documents scientifiques de niveau recherche, publiés ou non, émanant des établissements d'enseignement et de recherche français ou étrangers, des laboratoires publics ou privés. 


\title{
Land evaluation methodology and GIS for soil resource management. Example with cotton crop in Greece
}

\author{
Vassiliki J. Kollias*, Dionissios P. Kalivas \\ Department of Soil Science and Agricultural Chemistry, Agricultural University of Athens, Iera Odos 75, Botanicos 11855, Athens Greece
}

(Received 6 October 1998; accepted 24 December 1998)

\begin{abstract}
A geographical information system is presented that was developed for the automatic evaluation of the suitability of soil for selected agricultural uses. The properties that are used for soil evaluation are those included in the mapping symbols of the Greek soil maps. The land evaluation rules stored in the system were derived from the corresponding literature, the field experts and from local experience. The computerised system allows users to select an area, to evaluate the suitability of its soils for a number of crops and to present the results of the evaluation in a very straightforward manner. The soils of Karditsa in the area of Thessalia in central Greece were evaluated for growing cotton and the results of the evaluation are presented as an application example of the operation of the system. The system can be used for a fast, easy and consistent evaluation of existing soil maps in order to help agricultural extension services in land use planning and management without the necessity for advice from specialists. (ㅇ Inra/Elsevier, Paris.)
\end{abstract}

\section{land evaluation / soil classification / geographical information system / expert system}

Résumé - Caractérisation des terroirs à l'aide d'un SIG pour la gestion des ressources des sols. Exemple du coton en Grèce. Un système d'information géographique a été développé pour l'évaluation automatique des aptitudes des sols pour certaines utilisations agricoles. Les critères utilisés pour la caractérisation des sols sont ceux qui sont employés pour définir les unités sémantiques des sols de la carte pédologique de Grèce. Les règles d'évaluation des terroirs qui sont incorporées dans le système s'appuient sur la bibliographie, l'avis des experts de terrain et l'expérience locale. Le système informatique développé permet aux utilisateurs de choisir une région, d'évaluer l'aptitude des sols pour différentes cultures et de présenter les résultats de l'évaluation d'une manière facile à comprendre. Les sols de Karditsa, région de Thessalie en Grèce centrale, sont évalués pour la culture du coton et les résultats de l'évaluation sont présentés à titre d'exemple comme une application du fonctionnement du système. Celui-ci peut être utilisé pour évaluer de manière simple, facile et fidèle les potentialités des sols à partir des cartes pédologiques afin d'aider les services de développement agricole pour la planification et l'aménagement du territoire sans nécessiter l'intervention d'un spécialiste. (C) Inra/Elsevier, Paris.)

caractérisation des terroirs / classification des sols / système d'information géographique / système d'expert

Communicated by Gérard Guyot, (Avignon, France)

* Correspondence and reprints

1sos2kob@auadec.aua.gr 


\section{INTRODUCTION}

For many years the basic activity of the soil survey institutes of the Greek Ministry of Agriculture was to produce soil maps with associated reports, whose interpretation for agricultural uses was left to the users. Very often, the interpretation of the soil maps cannot be performed easily by those who are planning the agricultural policy and/or by those who are applying it.

Land evaluation is defined as the assessment of land performance when used for specific purposes [7], or according to Davidson [4], it is the assessment of the earth's capacity to provide proper nutrition to its human population in the years and decades to come. The aim of land evaluation is to provide land managers with information, which will improve the quality of land decisions and thus avoid the degradation and loss of agricultural lands resulting from bad management.

The land evaluation techniques $[7,8,19]$ that are used today for the estimation of the suitability of land resources for various agricultural uses produce maps which are readily understood by non-specialists. Operational procedures for land evaluation, defined by FAO [7, 8] have been widely applied all over the world. The land of the Nigerian Institute for Oil Palm Research's main station in southern Nigeria was evaluated for suitability for oil palm cultivation by the FAO system [16]. The suitability of the University of Zambia farm for selected crops was assessed using the principles and the concepts of the FAO framework for land evaluation [3]. A FAO land evaluation method validated by comparison of observed and predicted yields of five food crops in Burundi [10].

Manual procedures for land evaluation are time consuming and liable to error. Thus, there are merits for automating them. The Soil Survey and Land Research Centre (SSLRC) which is responsible for the classification and mapping of soils in England and Wales, has developed a national Land Information System for the storage and the evaluation of soil and land data [9]. Brisson et al. [2] describe a model suitable for studying large-scale spatial variation in land suitability which is able to use readily available input data.

Knowledge systems have been considered as a very useful approach for processing information for land evaluation $[1,11,12]$. The Automated Land Evaluation System (ALES) [17] is a micro-computer program that implements the FAO methodology. On the basis of the ALES framework, Yizengaw and Verheye [21] developed a simple computerised land evaluation system which was used for the suitability evaluation of annual food crops (barley, maize and teff) grown under subsistence rainfed conditions in central Ethiopia. On the other hand, the assessment of the land requires knowledge about processes that operate across geographic boundaries. Use of land and protection of the environment requires spatial information and any proposed changes and their impacts will also have spatial dimensions. With the development of GIS technology, the land managers have at their disposal information systems in which data are readily accessible and easily combined and modified.

The integration of the geographical information systems (GIS) with processes of land assessment, produces intelligent geographical information systems (IGIS) which overcome the inability of the conventional GIS to interpret the relationships between land qualities and land uses without the interventions of human advisors.

Many authors have promoted the integration of GIS with expert systems in order to support decision making in resource management $[14,15,22]$. Most of the early integrated systems require the users: a) to have considerable knowledge concerning the implementation details of the software packages that they are using, and b) to perform all the transferring between the software packages, since in most cases the latter operate in different programming environments.

The objective of this study was to design and implement a simple and easy-to-use IGIS that can be used as a tool by agricultural extension services for the assessment of the suitability of soils for various agricultural uses. The major aim in developing the system was to provide a mechanism to enable consistent evaluation of existing soil maps for agri- 
cultural uses to be carried out by non-experts. It was almost a key requirement in the system's development that it should be able to run on a standard IBM $\mathrm{PC}$, requiring minimal operational training.

The basic assumption on which the system has been built is that the soil is the major determinant of the crop yield, and that the quality and the quantity of soil resources are very important to farm productivity. Thus, at the present stage of its development, the system does not incorporate variations in climate and cultivation practices. The soil properties that were used in the evaluation are those contained in the mapping symbol of existing soil maps, because for the majority of maps which were produced by Greek soil surveys, the mapping symbol is the only common information which is readily available. The soil properties included in the Greek soil mapping symbol are: the drainage, the texture in three depths (surface 0-25 cm, subsoil $25-75 \mathrm{~cm}$ and substratum $75-150 \mathrm{~cm}$ ), the degree of horizon differentiation development, the slope, the erosion of the soil surface and the presence of calcium carbonates and gravel.

The geographic processing capabilities of the commercial GIS package PC ARC/INFO have been used for the development of the intelligent soil evaluation information system (ISEIS). Knowledgebased techniques for land evaluation were incorporated into the commercial GIS package PC ARC/INFO [6]. The simple macro language (SML) of PC ARC/INFO was used for the implementation of the system. The knowledge stored in ISEIS was derived from experiments, local experience and land evaluation literature. ISEIS works as a subsystem of PC ARC/INFO and communicates readily with its other subsystems. The communication with the users is made through menus. The modularity in the system design and implementation makes it very easy to use and to expand it with additional processes. ISEIS allows users to access PC $\mathrm{ARC} / \mathrm{INFO}$, to select an area, to evaluate the suitability of its soils for a number of crops and to present the results of the evaluation in various ways. All these processes are performed in a very simple way. Help facilities in each step of the evaluation inform the user about the processing possibilities that are provided by the system. The results of the application of the prototype system to the soils of an area of central Greece are presented.

\section{MATERIALS AND METHODS}

\subsection{Definition of the problem}

The identification of the optimum land use for sustainable agriculture is of major practical interest for Greece. Even though the Greek soil maps that exist today cover large agricultural areas, they nevertheless exhibit grave limitations that deter their broad use. These limitations are mainly due to the following two reasons. First, the soil maps in their present form offer very little help to middle users for the estimation of the potential of soils for various agricultural uses, and second, their mapping symbol is not very well understood by non-soil scientists. Consequently, very often soil resources are not used to their optimal potential.

In Greece, there has been a recent realisation that good quality soil is of very limited spatial extent. Conserving the soils from the degradation resulting either from the application of inappropriate agricultural uses or from a prolonged intensive agriculture, makes it imperative that the application of soil evaluation methodology is based on the available scientific knowledge and experimentation.

The basic feature of soil evaluation is the comparison of the requirements of a specific agricultural use with the potentials of the soils. Soil suitability is assessed in relation to particular agricultural uses. Fundamental to the evaluation procedure is the fact that different kinds of uses have different requirements. The definition of the soil requirements of a selected crop is the first step in order to convert existing soil maps into soil evaluation maps for that crop. Therefore, the minimum requirements for the application of a soil evaluation method are first, the existence of soil data and second, the description of the requirements of the desired agricultural use defined by a long-term educated knowledge and experimentation.

The soil suitability maps produced by soil evaluation procedures as interpretations of the soil conditions can be easily used by non-specialists and thus provide an effective way of presenting soil data in forms readily understood.

Soil evaluation requires a wide range of expertise from the biophysical to computational sciences. The application of land evaluation methodologies involves 
numerous repetitive calculations and references to tables. On the other hand, expert systems incorporate accumulated knowledge into computer programs.

The integration of GIS with an expert system might lead to a fast, effective and easy production of the soil evaluation maps that are required by land use planners, land evaluators and natural resources managers in order to perform their tasks. The application of alternative land use scenarios, the statistical and geostatistical analysis of data and results, and the production of thematic maps are some of the processes that are performed very efficiently by IGIS. On the other hand, the experienced personnel required for their operation is a serious drawback for their extensive use among the agricultural services. Surveys carried out among agricultural services in Greece have shown that $90 \%$ of them owned a personal computer and that $95 \%$ of the scientific personnel know how to use a computer. Therefore, the need for the development of a simple and easy-to-use system, which can evaluate the large volume of existing soil maps, for agricultural uses, by making use of well-defined crop requirements (which are now available after many years of experiments) and land evaluation methodologies, is apparent.

\subsection{Land evaluation methodology}

The assessment of the suitability of the soils has been based on the principles and suggestions of the world Food and Agriculture Organisation (FAO) framework for land evaluation $[7,8]$.

In the early 1970s, the Food and Agricultural Organisation realised the need for some kind of methodological framework to aid agricultural planning. The results from a series of international discussions are incorporated in A Framework for Land Evaluation [7]. The FAO framework is a set of methodological guidelines that can be applied to any evaluation project in any environmental situations and at any scale. It is a scheme for land suitability classification and provides suggestions that should be considered when evaluating land for specific purposes.

Three levels of classification are considered: land suitability orders, classes and subclasses. The suitability classes are assessed separately for each kind of land use under consideration, with respect to each soil mapping unit in the survey area.

The suitability orders separate land assessed as 'suitable', $\mathbf{S}$, from that which is 'not suitable', $\mathbf{N}$, for the use under consideration.
The suitability classes indicate degrees of suitability. Within the order 'suitable' three classes are defined: $\mathbf{S 1}$ (highly), S2 (moderately) and S3 (marginally). Within the order 'not suitable' two classes are defined, N1 (currently not suitable) and $\mathbf{N} \mathbf{2}$ (permanently not suitable).

The suitability subclasses indicate kinds of limitations, e.g. moisture deficiency and erosion hazard, and are defined by lower case letters placed after the class symbol. There is no limit to the number of subclasses that may be employed in a particular survey.

For each soil characteristic (i.e. a soil property that can be measured or estimated) used, the values that form the boundaries between suitability classes are determined using the knowledge of the local soil conditions, experimentation and the relevant literature.

Three evaluation methodologies have been incorporated into the system, for the assessment of the overall suitability of the soils, for the agricultural uses under consideration [19]. According to three evaluation methodologies the soils are classified into five suitability classes $\mathbf{S 1}, \mathbf{S 2}, \mathbf{S 3}, \mathbf{N 1}$ and $\mathbf{N 2}$. The overall suitability class for each soil mapping unit is a result of the combination of the suitability classes of the individual soil characteristics using the following procedures:

\subsubsection{The simple limitation method}

The soil characteristics are compared to the crop soil requirements and the soil suitability class is attributed according to the less favourable characteristics. Thus, soil rated as $\mathbf{S 1}$ on drainage conditions, $\mathbf{S 1}$ on carbonates conditions and $\mathbf{S 3}$ on erosion hazard would be assessed overall as $\mathbf{S 3}$. The kinds of limitations that cause lowering of suitability are the basis for allocating subclasses. A lower case letter indicating the most limiting characteristic is used as a subclass symbol $(\mathbf{S} 3 \boldsymbol{e})$. The subclasses used are: $s$ for slope, $d$ for drainage, $t 1, t 2, t 3$ for texture of $0-25,25-75$ and $75-150 \mathrm{~cm}$ deep, respectively, $c$ for carbonates and $e$ for erosion.

\subsubsection{The multiple limitation method}

This is a limitation method, with the number and intensity of the limitations as criteria. In this method, the evaluation is performed by comparing the soil characteristics to the limitation levels of the crop requirements [19]. Five limitation levels are used: no limitations (0), slight limitations (1), moderate limitations (2), severe limitations (3) and very severe limitations (4).

The suitability classes are defined as follows: 
S1: highly suitable, soil units with no or up to 3 or 4 slight limitations;

S2: moderately suitable, soil units with more than 3 or 4 slight limitations, and/or one or more severe limitations;

S3: marginally suitable, soil units with more than 2 or 3 moderate limitations and/or one or more severe limitations;

N1: currently unsuitable, soil units with very severe limitations that can be corrected;

N2: permanently unsuitable, soil units with very severe limitations that cannot be corrected.

The multiple limitation method is more reliable than the simple limitation method. Just one characteristic, the least suitable, decides the overall suitability class by the simple limitation method, but the multiple limitation method considers all the characteristics.

\subsubsection{The parametric method}

In the parametric method, a numerical rating is attributed to the limitation levels for each soil characteristic and then an overall score is determined by the use of a multiplicative model.

A soil index is calculated using the individual ratings. For the calculation of this soil index $(S I)$ the following procedure is applied:

$$
S I=A \times \frac{B}{100} \times \frac{C}{100} \times \ldots
$$

where A, B, C, etc., are the numerical ratings of the individual soil characteristics. These numerical ratings are defined from the literature, the field experiments and the expert judgement.

Suitability classes are defined according to the value of the soil index:

$$
\text { S1: 100-75; S2: 75-50; S3: 50-25; N: 25-0. }
$$

The problem with parametric methods is that limitations have a synergistic multiplicative effect. They usually overestimate the synergistic effect of multiple limitations.

Although there is considerable merit in being able to produce a number, which expresses the suitability of the soil for one or more specific crops, the parametric method has been incorporated into the system in order to be used from those users who want to study the soil factors that affect the performance of the soils for specific crops, and to devise an index for rating the soil quality.
Also this method is more reliable than the other two because it considers all the individual characteristics to form the overall suitability class, while just one that is least suitable decides the overall suitability class by the simple limitation method.

Thus, the efficiency of each method depends to a large extent on the relative importance of the most limiting characteristic to the crop under consideration. If the most limiting characteristic is an important soil property, which dominates the performance of the crop, then the simple limitation or the multiple limitation methods may be more accurate. In the case that the most limiting characteristic is a soil characteristic that can be corrected, then the parametric methods will be more appropriate.

\subsection{The ISEIS system}

The ISEIS system was designed and implemented using the IF-THEN methodology of the rule-based systems which is recognised as a very useful approach for organising relevant heuristic knowledge and analytical information for natural resources assessment [15].

A rule-based system is a simple expert system that uses a series of rules structured in a logical sequence for solving problems that normally call for expert knowledge and judgement.

Knowledge rules for soil evaluation were incorporated into the commercial GIS package PC ARC/INFO using the SML (simple macro language) programming language of PC ARC/INFO. The fact that the system operates as an PC ARC/INFO subsystem enhances its spatial processing capabilities compared to those of ARC/INFO.

Spatial and tabular data of existing soil maps were stored in ISEIS.

Expert systems incorporate accumulated expert knowledge into knowledge bases. The knowledge acquisition was the major problem in building the knowledge bases of the ISEIS system. Field experts (e.g. soil scientists, agricultural service agents, farmers), technical reports, published and unpublished material and experimentation were used as knowledge sources.

The soil requirements for each crop were implemented as a set of IF-THEN production rules in a separate knowledge base. ISEIS involves 12 discrete knowledge bases, one for each of the following crops: wheat, maize, cotton, barley, tobacco, potato, tomato, grapevines, olive, citrus, sugar beet and alfalfa. The ISEIS system 
has the major components of an expert system: a set of expert rules, a soil database and a inference system.

The main logical component of an expert system is the inference system, which contains the procedures for reasoning and for making conclusions using the knowledge base.

The reasoning mechanism of the ISEIS system is very simple and works quite satisfactorily for the type of problem examined. When the system is asked to reason for a conclusion, the values and the suitability classes of the corresponding soil attribute or set of attributes are displayed on the screen. Therefore, verification of the conclusion is possible.

The same general system is used for all the stored knowledge bases by simply unloading one set of rules and loading another. In developing the system, emphasis has been placed on avoiding inefficiencies due to duplication of effort both in analysis, design and coding of the programs.

The ISEIS system guides the user to: a) select the area to work with; b) select the crop of interest; c) select the evaluation method; d) evaluate the soils of the entire area of a map or of parts of it, according to the soil requirements of the selected crop; e) store the results of the evaluation of the suitability of each mapping unit and of each soil property for further processing and display; f) access the databases and display spatial and tabular data and the evaluation results; g) produce statistics concerning the number of occurrences, the area and the distribution of each suitability class; h) display the results of the evaluation in various ways. The system also provides helpful information concerning the selected area, the crops whose soil requirements are stored, the land evaluation methods and the operation of the system.

The users communicate with the system through menus with a tree structure. This type of structuring and the help commands in every step of the evaluation enables inexperienced users to communicate with the system very easily.

In the flow diagram of figure 1 the general structure of the system is presented.

\section{CASE STUDY}

\subsection{Study area}

An area of about 7500 ha in Karditsa, central Greece was selected to present the operation of

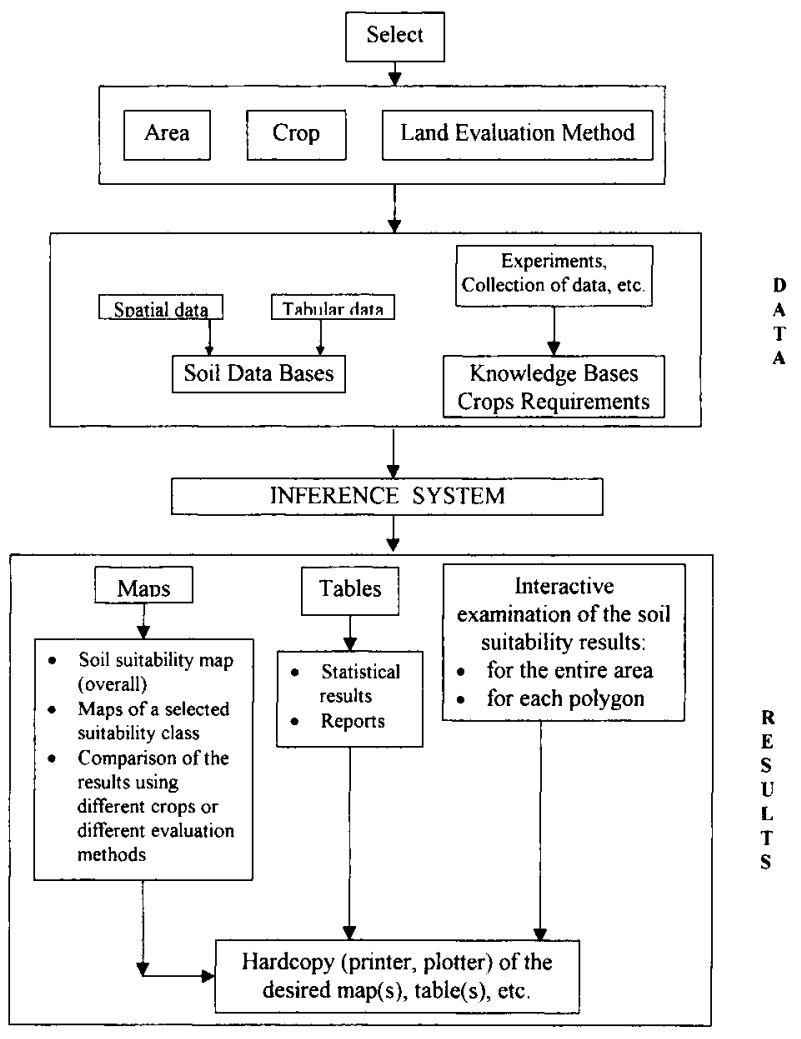

Figure 1. The general structure of the ISEIS system.

ISEIS system. The major agricultural use of the area is the cotton crop ( $85 \%$ ). Other agricultural uses are: maize $(10 \%)$ and alfalfa.

The area is flat, with slopes which range between 0 and $2 \%$. The soils of the area are classified according to the Soil Taxonomy classification system [18] as: inceptisols (55\%); alfisols (25\%); entisols $(13.5 \%)$ and vertisols $(6.5 \%)$. The soil maps of the Karditsa area, at a scale 1:20 000, were obtained from a soil survey of the area, which was conducted by the Soil Science Institute of Larissa of the National Agricultural Research Foundation.

Fifty-two different mapping units in 91 polygons were identified in the area. Each mapping unit was assumed to be homogeneous in terms of its physical and chemical properties. The soil orders of the area are presented in the map of figure 2 . 


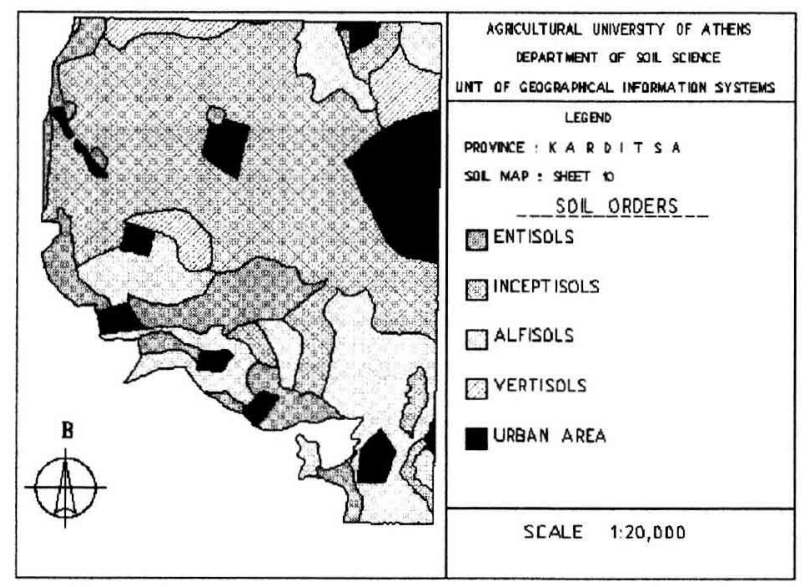

Figure 2. The map of the soil orders of the Karditsa area.

The climatic characteristics of the area are: mean annual temperature $15.8{ }^{\circ} \mathrm{C}$ and mean annual precipitation $788 \mathrm{~mm}$.

\subsection{Soil requirements for growing cotton crop}

The estimation of the soil suitability entails the assessment of the soil mapping units with respect to agricultural uses, which are physically and economically appropriate to the area. The land-use planning requires insight into present land use and the degree to which this fulfils human needs and the conservation of natural resources. The cultivation of the cotton crop is one of the major agricultural uses of the study area.

In general, the selection of the soil properties, which will be used in a soil evaluation project, is based on the effects of the properties upon the particular land use.

The soil properties that are used in ISEIS are: drainage, texture in three depths $(0-25 \mathrm{~cm}$, $25-75 \mathrm{~cm}, 75-150 \mathrm{~cm}$ ), slope, erosion and carbonates. As already mentioned, these properties are included among the mapping symbols and comprise the only common readily available information of the Greek soil maps. They have significant effects on most kinds of land use and from those, important information concerning moisture and nutrient availability, nutrient retention, erosion hazard, rooting conditions and water availability can be extracted. For example, available water capacity, rooting conditions, nutrient availability and soil moisture regime can be affected by the texture.

The assessment of the soil requirements of the cotton crop was based on 4-year experiments [13]. At the same time, a big volume of data concerning the yield and the soil properties under consideration was collected at selected areas. More particularly, yield data were collected from all the different mapping units of the area. For each soil property used, the values that form the boundaries between the suitability classes (S1, S2, S3, N1, N2) were estimated by production functions, which correlate yield data to the soil properties. Statistical modelling was used to formulate multiple regression equations for correlating yields of the cotton crop to the soil properties [13]. The resulting soil requirements of the cotton crop are presented in table $I$. The results found, were in accordance with those reported by Sys [19] and Doorenbos and Kassam [5].

For the parametric method, the numerical rating of the nominal scale attributes of table $I$ is performed using a look-up table based on the field experiments and the expert's judgement.

\subsection{Operation of the system}

The operation of the system will be presented through the evaluation of the soils of the study area for the cotton crop. Each step of the evaluation will be explained and presented in detail.

Step 1: communication with the system starts when the user runs the ISEIS. First, a general description of the system as presented in the flow diagram of figure $l$ and an associated text concerning its operation and the facilities provided can be displayed on the screen as a selection from a menu. Subsequently, a map is displayed on the screen of Greece whose provinces, for which soil data have been stored in the system, are shown in black. The 
Table I. The requirements of the cotton crop for the soil parameters included in the Greek soil mapping symbol.

\begin{tabular}{|c|c|c|c|c|c|c|}
\hline \multirow{4}{*}{ Soil parameters } & \multicolumn{6}{|c|}{ Suitability classes } \\
\hline & \multicolumn{2}{|c|}{ S1 } & & S3 & NI & $\mathrm{N} 2$ \\
\hline & \\
\hline & 0 & 1 & 2 & 3 & 4 & 4 \\
\hline Slope (\%) & $0-2$ & $2-6$ & $6-12$ & $12-18$ & $18-25$ & $25-35$ \\
\hline Drainage & $\mathrm{A}, \mathrm{B}$ & $\mathrm{B}$ & C, D & $\mathrm{E}, \mathrm{F}$ & $\mathrm{G}$ & $\mathrm{G}$ \\
\hline $\begin{array}{l}\text { Texture } \\
0-25 \mathrm{~cm}\end{array}$ & & $\begin{array}{c}\mathrm{SiL}, \\
\mathrm{Si}, \\
\mathrm{SCL}, \\
\mathrm{CL}, \\
\mathrm{SiCL}\end{array}$ & $\begin{array}{c}\text { SL, } \\
\text { SC, } \\
\text { SiC, } \\
\text { C }\end{array}$ & $\begin{array}{l}\text { S, } \\
\text { LS }\end{array}$ & $\begin{array}{l}\text { Gravels } \\
>60 \%\end{array}$ & \\
\hline $\begin{array}{l}\text { Texture } \\
25-75 \mathrm{~cm}\end{array}$ & $\begin{array}{c}\mathrm{C}, \\
\mathrm{SiC}, \\
\mathrm{SC}\end{array}$ & $\begin{array}{l}\mathrm{CL}, \\
\mathrm{SiCl}, \\
\mathrm{SCL}\end{array}$ & $\begin{array}{c}\mathrm{Si} \\
\mathrm{SiL} \\
\mathrm{L}\end{array}$ & $\begin{array}{l}\text { S, } \\
\text { LS, } \\
\text { SL }\end{array}$ & & \\
\hline $\begin{array}{l}\text { Texture } \\
75-150 \mathrm{~cm}\end{array}$ & $\begin{array}{c}\text { more } \\
\text { fine than } \\
\mathrm{L}\end{array}$ & $\begin{array}{c}\mathrm{Si} \\
\mathrm{SiL} \\
\mathrm{L}\end{array}$ & $\begin{array}{l}\text { SL, } \\
\text { LS, } \\
\text { S }\end{array}$ & & & \\
\hline Carbonates & 0 & & 1 & 2 & 3 & \\
\hline Erosion & 0 & 1 & 2 & 3 & 4 & \\
\hline
\end{tabular}

Drainage - A: very well drained; B: well drained; C: moderately well drained; D: somewhat poorly drained; E: poorly drained; F, G: very poorly drained.

Erosion - 0: no erosion; 1 : slightly eroded; 2 : moderately eroded; 3 : very eroded; 4 : severely eroded.

Carbonates - 0: no reaction throughout the soil profile; 1 : some reaction occurs deeper than $25 \mathrm{~cm}$; : slight reaction in the surface layer, while the reaction in the deeper sections is not considered; 3: strong reaction in the surface layer, while the reaction in the deeper sections is not considered.

Texture - Si: silt; SiL: silty loam; SiCL: silty clay loam; SiC: silty clay; L: loam; LS: loamy sand; C: clay; CL: clay loam; S: sand; SL: sandy loam; SC: sandy clay; SCL: sandy clay loam.

user selects the province, which contains the area for evaluation, by clicking on the appropriate place on the map or by typing its name on the associated menu.

Step 2: since for each province more than one soil map sheet is stored in the database, the selection of the province is followed by the selection of a specific area within it. Once again, a graphical display of the province with the geographical places of the stored soil maps and an associated menu are displayed on the screen.
Step 3: when the desired soil map has been selected, the next step is to select one crop from a list of crops whose soil requirements are stored in the system. When a crop is selected, the areas for which the crop requirements have been tested using yield data are displayed on the screen.

Step 4: since more than one evaluation procedure is stored in the knowledge base of the system the user is prompted to choose one of them.

Step 5: now, the system goes on to estimate for each mapping unit first, the suitability class of each 
soil attribute included in the mapping symbol and second the overall suitability of the mapping unit according to the selected evaluation method. Before the selected evaluation method is applied, the user is asked whether he wants to follow the details of the evaluation. If the answer is yes, the system presents to the user the evaluation results of each soil attribute and the overall suitability of every polygon of the map.

Step 6: when the evaluation of the entire map has been completed, the user is asked whether he wants to repeat the estimation process with another evaluation method, or with another crop for the same or different area. Steps 1-5 are presented in the flow diagram of figure 3 .

The system supports a variety of ways for displaying the data and the results.

Maps of the entire area or of selected polygons, classified in suitability classes according to a selected evaluation method, can be easily derived as has been presented in the flow diagram of figure 3. These maps might concern the evaluation either of one or more soil properties or of the entire mapping symbol of a single polygon, a set of polygons or of all the polygons in the map. The results of the two or three evaluation methods for the same or for different crops can be displayed at the same time on the screen (or hard copy) as a composite map.

A single polygon or a set of polygons can be selected for display and analysis by either a) writing their code numbers, b) clicking on them with the screen cursor or c) defining a spatial window on the screen as an answer to the options of a menu table.

When the evaluation process is terminated, the user is asked if he wants to know 'why' a suitability class has been assigned either to a specific mapping unit or to the mapping units of the area which has been evaluated (a set of polygons or the entire map).

By the user clicking on a specific mapping unit, the values of the individual soil variables of that unit and their suitability classes as well as the suitability class of the corresponding mapping symbol are displayed on the screen.
Table II. The percentage of soils which were classified in each suitability class, using the simple limitation method and the multiple limitation method.

\begin{tabular}{lccccc}
\hline $\begin{array}{l}\text { Evaluation } \\
\text { method }\end{array}$ & \multicolumn{4}{c}{ Soil suitability classes } & $\begin{array}{c}\text { Urban } \\
\text { area }\end{array}$ \\
\cline { 2 - 5 } & $\begin{array}{c}\mathrm{S} 1 \\
(\%)\end{array}$ & $\begin{array}{c}\mathrm{S} 2 \\
(\%)\end{array}$ & $\begin{array}{c}\text { S3 } \\
(\%)\end{array}$ & $\begin{array}{c}\mathrm{N} 1 \\
(\%)\end{array}$ & $(\%)$ \\
\hline Simple limitation & 46.8 & 37.8 & 0.7 & 3.5 & 11.2 \\
Multiple limitation & 46.7 & 37.5 & 1.1 & 3.5 & 11.2 \\
\hline
\end{tabular}

In the case when the entire map is to be examined, the code number, the suitability class and the most limiting soil variable of each polygon are displayed on the screen. At the same time, the corresponding mapping unit of the map is painted red on the screen.

The previously described process is a simple but quite flexible and satisfactory reasoning mechanism, which can be used for the examination of the evaluation results.

Statistics concerning the distribution of the suitability classes of the derived maps can also be obtained through a number of menus.

\section{RESULTS}

The percentages of soils, which are classified in each suitability class, are given in table $I I$. The results presented were obtained using the simple limitation and multiple limitations evaluation methods.

As is shown in table $I I$ more than $84 \%$ of the soils of the study area were classified as suitable (classes $\mathbf{S 1}$ and $\mathbf{S 2}$ ) for the cultivation of the cotton crop using the two evaluation methods. Mainly sandy soils were classified as marginally suitable (class S3), while soils with more than $60 \%$ gravel at any depth of the soil profile were classified as currently unsuitable (N1). Permanently unsuitable soils were not detected in the area. Since the majority of soils of the area are suitable for growing cot- 


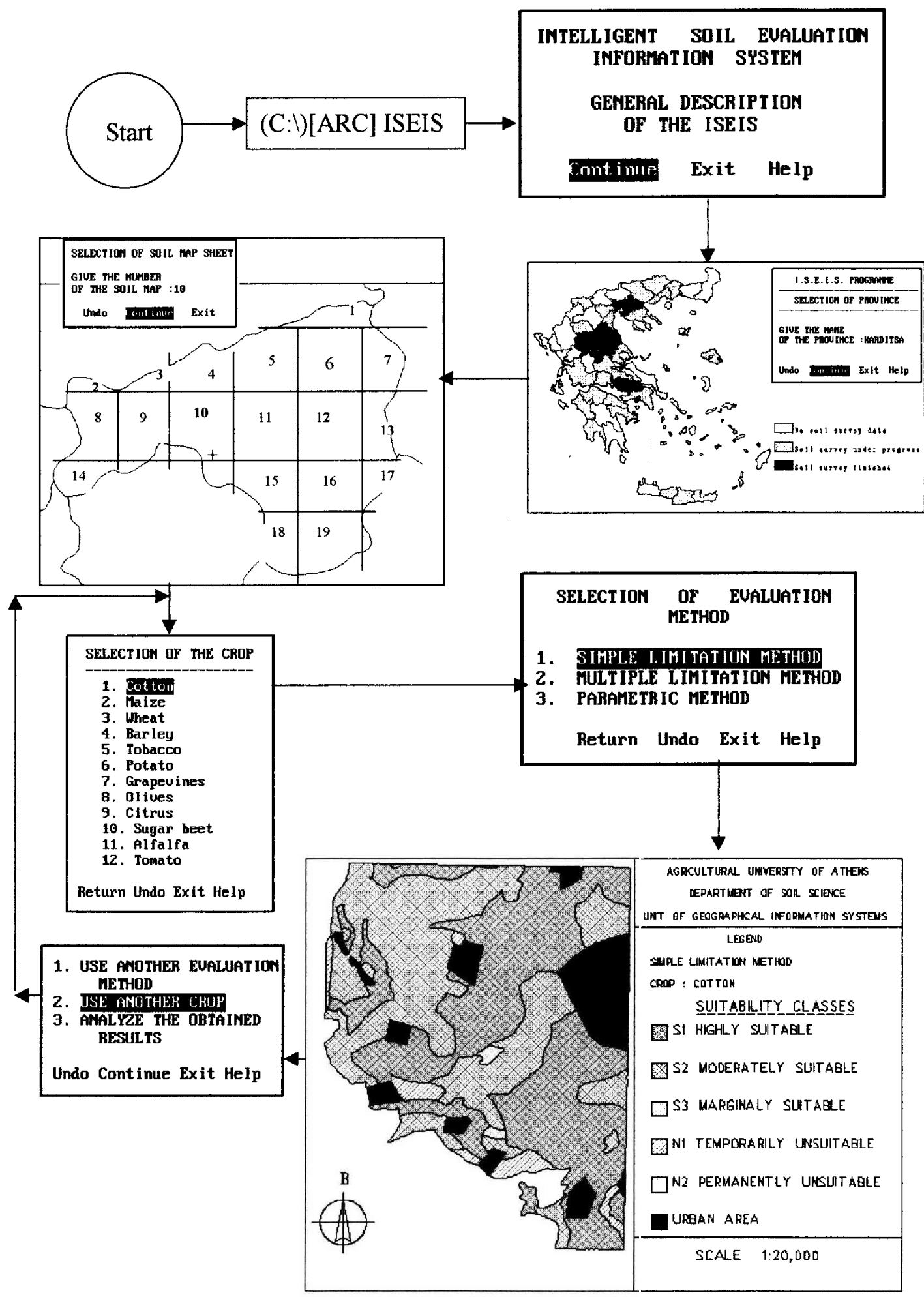

Figure 3. The flow diagram of the evaluation procedure of the soils of Karditsa for cotton crop. 
ton, the two evaluation methods give almost the same results.

The ISEIS is currently being validated by soil and agronomy experts in several Greek areas. No standard guidelines for an acceptable validation of the land evaluation results exist. The crop yields proved to be the most reliable estimates of comparative value for agricultural soil evaluation. Although the evaluation generated by ISEIS has not yet been tested using field investigations, the cotton crop yields in the study area correspond fairly well with the assessment given by the ISEIS, system as verified by local experts and farmers. The average cotton yields of the area are: $3.9,3.1,2.5$ and 1.8 ton/ha from soil suitability classes $\mathbf{S 1}, \mathbf{S 2}, \mathbf{S 3}$ and $\mathbf{N 1}$, respectively. The system provides an indication of which areas may be suitable for the cotton crop but does not give an indication concerning the most profitable areas from an economic viewpoint.

\section{DISCUSSION AND CONCLUSIONS}

The paper presents an intelligent geographical information system for the evaluation of existing Greek soil maps, for various agricultural uses, using the soil attributes that are included in their mapping symbols. In particular, the system converts the difficult to interpret and use soil maps into readily understood soil suitability maps for agricultural uses.

The system was developed using an IBM compatible PC because the majority of Greek agricultural co-operatives and extension services, which are the most likely users of the system, owns a PC. This very simple platform configuration keeps the overall cost of the system (software and hardware) at very low levels.

The implementation of the system as an expert subsystem of PC ARC/INFO, using the SML language, enhances its geographical capabilities as compared to those of PC ARC/INFO. Additionally, the operation of the system through menus enables the users to avoid the operation details of the tools employed in the system.

The system produced can be used by the Greek agricultural extension services and the local agri- cultural authorities of each area, for the estimation of the suitability of the soils for various crops, in order to increase the yield and to reduce the effects of intensive cultivation on soil quality. Moreover, this simple tool can utilise available expert knowledge and data in an efficient manner.

The storage of the soil requirements of a number of different crops presents the policy maker with the necessary information to change land use and reduce the damage to the environment. The system allows crops to be targeted on areas most suitable for these crops.

Further work is oriented towards the storage in the system of all existing Greek soil maps and the soil requirements of a large number of crops, which are either already cultivated or which are going to be tested on an area. It is more likely that in each area, information will be asked by the users concerning their soil. Therefore, in order to keep the hardware cost low, only the soil maps of each particular area will be stored in the local geographical database of the system.

At a later stage of the system's development, variations in climate and agricultural management practices will be incorporated into the ISEIS. Also, the suitability classes will be analysed economically and adjusted if necessary. Thus, the best soils will be determined not only by their ability to produce high yields but also by their ability to achieve these yields at the least cost.

Finally, the ISEIS system offers the potential of codifying and disseminating expertise to those who do not have it and promises that expert knowledge will be at everyone's disposal.

Acknowledgement: We are grateful to the staff of the Soil Science Institute of Larissa of the National Agricultural Research Foundation for providing the data. Special thanks to G. Papathanasiou for assistance with the preparation of the maps.

\section{REFERENCES}

[1] Bouma J., Wagenet R.J., Hoosbeek M.R., Hutson J.L., Using expert systems and simulation modelling for land evaluation at farm level: a case study from New York State, Soil Use and Manage. 9 (1993) 131-139. 
[2] Brisson N, King B., Ruget D., Ripoche D., Darthout R., A crop model for land suitability evaluation: a case study of the maize crop in France, Eur. J. Agron. 1 (1993) 163-175.

[3] Chinene V.R.N., Land evaluation using the FAO framework: an example from Zampia. Soil Use and Manage. 8 (1992) 130-139.

[4] Davidson D. A., The Evaluation of Land Resources, John Wiley \& Sons, Inc., New York, 1992.

[5] Doorenbos J., Kassam A.H., Yield response to water, Irrig. Drainage Paper 33, Rome, FAO, 1979.

[6] ESRI, PC ARC/INFO ver. 3.5.1, ESRI, Redlands, California, 1997.

[7] FAO (Food and Agriculture Organisation), A framework for land evaluation, FAO Soils Bulletin No. 32, FAO Rome, 1976.

[8] FAO (Food and Agriculture Organisation), Guidelines: Land evaluation for irrigated agriculture, FAO Soils Bulletin No. 55, FAO Rome, 1985.

[9] Hallet S.H., Jones R.J.A., Keay C.A., Environmental information systems developments for planning sustainable land use, Int. J. Geogr. Inform. Syst. 10 (1996) 47-64.

[10] Hennebert P.A., Validation of a FAO evaluation method by comparison of observed and predicted yields of five food crops in Burundi, Soil Use Manage. 12 (1996) 134-142.

[11] Jonson A.K.L., Cramb R.A., Development of a simulation based land evaluation system using crop modelling, expert systems and risk analysis, Soil Use Manage. 7 (1991) 239-246.

[12] Johnson A.K.L., Cramb R.A., McAlpine J.R., Integration of biophysical and economic data using an expert system: from a case study in northern Australia, Soil Use Manage. 10 (1994) 181-188.

[13] Kalivas D.P., Land evaluation of agricultural soils in Thessalia plain for high capital investement crops (in Greek), Ph.D. thesis, Agricultural University of Athens, 1991.

[14] Loh D.K., Rykiel E.J. Jr, Integrated resource management systems: coupling expert systems with database management and geographic information systems, Environ. Manage. 16 (1992) 167-177.

[15] Loh D.K., Hsieh Y.T.C., Choo Y.K., Holtfrerich D.R., Integration of a rule based expert system with GIS through a relational database management system for forest resource management, Comput. Electron Agric. 11 (1994) 215-228.

[16] Ogunkunte A.O., Soil in land suitability evaluation: an example with oil palm in Nigeria, Soil Use Manage. 9 (1993) 35-40.

[17] Rossiter D.G., ALES. A framework for land evaluation using a microcomputer, Soil Use Manage. 6 (1990) 7-20.

[18] Soil Survey Staff, Soil Taxonomy: A basic system of soil classification for making and interpreting soil surveys, USDA Agriculture Handbook No. 436, Washington, DC, 1975.

[19] Sys C., Land evaluation, Parts I-IV, International Training Centre for Postgraduate Soil Scientists, State University of Ghent, Ghent, 1985.

[20] Yassoglou N., Nychas A., Kosmas K., Parametric designation of mapping units for soil survey and evaluation in Greece base on soil taxonomy, Am. Soc. Agric. Annual Meetings, Anacheim, California, 1982.

[21] Yizengaw T., Verheye W., Application of computer captured knowledge in land evaluation, using ALES in central Ethiopia, Geoderma 66 (1995) 297-311.

[22] Zhu X., Aspinall R.J., Healey R.G., ILUDSS: A knowledge-based spatial decision support system for strategic land-use planning, Comput. Electron. Agric. 15 (1996) 279-301. 